\title{
Particle Size and Pore Structure Characterization of Silver Nanoparticles Prepared by Confined Arc Plasma
}

\author{
Mingru Zhou,, ${ }^{1,2}$ Zhiqiang Wei, ${ }^{2,3}$ Hongxia Qiao,, ${ }^{1,2}$ Lin Zhu, ${ }^{3}$ Hua Yang, ${ }^{3}$ and Tiandong Xia ${ }^{2}$ \\ ${ }^{1}$ School of Civil Engineering, Lanzhou University of Technology, Lanzhou 730050, China \\ ${ }^{2}$ State Key Laboratory of Advanced New Nonferrous Materials, Lanzhou University of Technology, Lanzhou 730050, China \\ ${ }^{3}$ School of Science, Lanzhou University of Technology, Lanzhou 730050, China
}

Correspondence should be addressed to Zhiqiang Wei, zqwei7411@163.com

Received 24 September 2008; Accepted 18 November 2008

Recommended by Jose A. Pomposo

\begin{abstract}
In the protecting inert gas, silver nanoparticles were successfully prepared by confined arc plasma method. The particle size, microstructure, and morphology of the particles by this process were characterized via X-ray powder diffraction (XRD), transmission electron microscopy (TEM) and the corresponding selected area electron diffraction (SAED). The $\mathrm{N}_{2}$ absorptiondesorption isotherms of the samples were measured by using the static volumetric absorption analyzer, the pore structure of the sample was calculated by Barrett-Joyner-Halenda (BJH) academic model, and the specific surface area was calculated from Brunauer-Emmett-Teller (BET) adsorption equation. The experiment results indicate that the crystal structure of the samples is face-centered cubic (FCC) structure the same as the bulk materials, the particle size distribution ranging from 5 to $65 \mathrm{~nm}$, with an average particle size about $26 \mathrm{~nm}$ obtained by TEM and confirmed by XRD and BET results. The specific surface area is $23.81 \mathrm{~m}^{2} / \mathrm{g}$, pore volumes are $0.09 \mathrm{~cm}^{3} / \mathrm{g}$, and average pore diameter is $18.7 \mathrm{~nm}$.
\end{abstract}

Copyright (C) 2009 Mingru Zhou et al. This is an open access article distributed under the Creative Commons Attribution License, which permits unrestricted use, distribution, and reproduction in any medium, provided the original work is properly cited.

\section{Introduction}

Nanoparticles exhibit novel properties that significantly different from those of corresponding bulk solid-state owing to the small size effect, surface effect, quantum size effect and quanta tunnel effect $[1-5]$. During the past years, the investigation for metal nanoparticles has attracted considerable attention due to their novel physical and chemical properties and potential application in diverse areas, such as catalyst, microelectronic elements, photoelectronic devices, lubricants, conductive materials, activation, and sintering materials [6-11]. All these application aspects require the powders consisting of monodisperse particles with desired physical and chemical properties. Many unique properties of nanocrystalline materials are mainly related to the particle size and pore structure [12-16]. The investigation on the particle size and pore structure for nanoparticles is essential to fully understand the structure of a nanocrystalline material as well as to the explanation of the intriguing properties, and it offers the possibility to obtain nanoparticles with desired physical and chemical properties.
Arc plasma method is a mature and advanced materials processing technique, and many metal nanoparticles have successfully been prepared by this method in the past [1618]. Compared with the conventional methods, confined arc plasma method has been proven to be suitable for production of metal nanopowders with ultrafine particle size, higher purity, narrow size distribution, well dispersed, and spherical shape. In addition, the physical and chemical properties of the nanopowders by this method can be easily improved by varying the processing parameters. Especially, it is a convenient, inexpensive process, and suitable for mass production in the industry [19]. However, to the best of our knowledge, there is no report on the preparation of uniform and monodisperse Ag nanoparticles in high yield by arc plasma method. In this paper, silver nanoparticles were successfully prepared by confined arc plasma technique in inert atmosphere. In addition, the particle size, lattice parameter, microstructure, morphology, specific surface area, and pore parameters of the samples by this process were characterized via X-ray powder diffraction (XRD), transmission electron microscopy (TEM), the corresponding selected area electron 
diffraction (SAED), and static volumetric absorption analyzer, and the results were discussed.

\section{Experimental}

Silver nanoparticles were prepared by confined arc plasma technique in inert atmosphere with home-made experimental apparatus described elsewhere $[18,19]$. In the process of preparation, the vacuum chamber was pumped to $10^{-3} \mathrm{~Pa}$ and then was backfilled with inert gas near to $10^{3} \mathrm{~Pa}$. The electric arc in the inert environment was automatically ignited between the wolfram electrode and the nozzle by high-frequency initiator. Under argon pressure and electric discharge current, the ionized gases were driven through the nozzle outlet and form the plasma jet [20]. The bulk metal silver (purity 99.99\%) was heated and melted by the high temperature of the plasma, metal atom detached from the metal surface when the plasma jet kinetic energy exceeds the metal superficial energy and evaporated into atom soot. Above the evaporation source, there is a region filled with supersaturated metal vapor, where the metal atoms diffused around and collided with each other to decrease the nuclei forming energy. When the metal vapor was supersaturated, a new phase was nucleated homogeneously out of the aerosol systems [21]. The droplets were rapidly cooled and combined to form primary particles by an aggregation growth mechanism [22]. The free inert gas convection between the hot evaporation source and the cooled collection cylinder transported the particles out of this nucleation and growth region to the inner walls of the cylinder. The loose nanoparticles could be obtained after a period of passivation and stabilization with working gas.

Table 1 shows the referential technological parameters of preparing silver nanoparticles by confined arc plasma method. To investigate the structure of the samples, the asobtained nanoparticles were analyzed by a rotating target $\mathrm{X}$-ray diffractometer (Japan Rigaku D/Max-2400) equipped with a monochromatic high-intensity $\mathrm{Cu}$ Ka radiation $(\lambda=$ $1.54056 \AA, 40 \mathrm{kV}, 100 \mathrm{~mA}$ ), The X-ray powder diffraction data were recorded in a range from 30 to $100^{\circ}(2 \theta)$ with scanning rate $0.005^{\circ} / \mathrm{s}$ and step size $0.02^{\circ}$. The average grain size of the nanoparticles was estimated from the halfmaximum width and the peak position of an XRD line broadened according to the Scherrer formula.

The particle size and morphology of the sample and the corresponding selected area electron diffraction (SAED) were examined by transmission electron microscopy (TEM) and Japan JEOL JEM-1200EX microscope with an accelerating voltage of $80 \mathrm{kv}$, respectively. In the process of preparation of the TEM specimen, a small amount of the powders was dispersed in a few milliliters of normal butanol in an ultrasonic bath and sonicated for 30 minutes, and a drop from an eye dropper of this dispersion sample was placed on a copper grid coated with holey carbon film. The samples were placed in a vacuum oven to dry at ambient temperature before examining. The sample is scanned in all zones before the picture is taken.

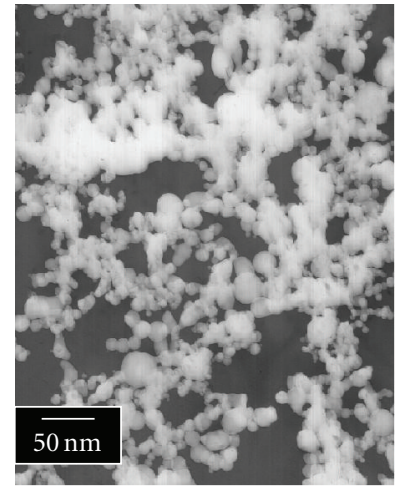

(a)

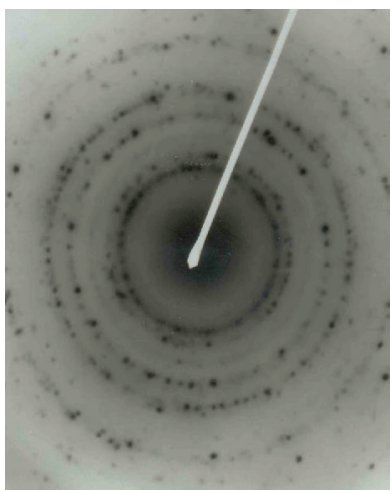

(b)
FIGURE 1: (a) TEM micrograph and (b) the selected area electron diffraction pattern of Ag nanoparticles.

The $\mathrm{N}_{2}$ absorption-desorption isotherms of the samples at liquid nitrogen temperature $(78 \mathrm{~K})$ and gas saturation vapor tension range were measured by using the ASAP 2010 static volumetric absorption analyzer produced by Micromerities Corp., NY, USA. Approximately 0.3 to $0.5 \mathrm{~g}$ of powder were placed in a test tube and allowed to degas for 2 hours at $175^{\circ} \mathrm{C}$ in flowing nitrogen. This removes contaminants such as water vapor and adsorbed gases from the samples. The static physisorption isotherms were obtained with $\mathrm{N}_{2}$ in liquid nitrogen, the amount of liquid nitrogen adsorption, or desorption from the material as a function of pressure $\left(P / P_{0}=0.025-0.999\right)$. Data were obtained by admitting or removing a known quantity of adsorbing gas in or out of a sample cell containing the solid adsorbent maintained at a constant temperature $(77.35 \mathrm{~K})$. As adsorption or desorption occurs, the pressure in the sample cell changes until equilibrium is established. From the $\mathrm{N}_{2}$ static physisorption isotherm of the samples to obtain the single layer adsorption capacity, the specific surface area of the sample was calculated from the BET adsorption equation. Based on the $\mathrm{BJH}$ academic model, the properties of the cumulative pore specific surface area, cumulative pore volume, average pore diameter, and $\mathrm{BJH}$ desorption pore distribution curves of the samples were estimated by $\mathrm{BJH}$ analysis method.

\section{Results and Discussion}

Figure 1(a) shows the representative transmission electron microscopy image of Ag nanoparticles. The TEM observation shows that the morphology of $\mathrm{Ag}$ nanoparticles is monodisperse; most of them are quasispherical shapes with smooth surface and uniform size. Some small particles aggregate into secondary particles because of their extremely small dimensions and high-surface energy.

Figure 1(b) shows the corresponding selected area electron diffraction (SAED) pattern. It can be indexed to the reflection of face-centered cubic (FCC) structure in crystallography, and this result was also investigated by means of X-ray diffraction. Tropism of the particles at random 
TABLE 1: Referential technological parameters of preparing metal nanoparticles by confined arc plasma.

\begin{tabular}{lcccccc}
\hline Gas pressure & Atmosphere & Arc voltage & Arc current & Cooled condition & Yield rate & Particle size \\
\hline $0.4 \sim 1.4 \mathrm{KPa}$ & $\mathrm{He}, \mathrm{N}_{2}, \mathrm{Ar}$ & $20 \sim 30 \mathrm{~V}$ & $60 \sim 160 \mathrm{~A}$ & Water & $0.5 \sim 1.3 \mathrm{~g} / \mathrm{min}$ & $20 \sim 100 \mathrm{~nm}$ \\
\hline
\end{tabular}

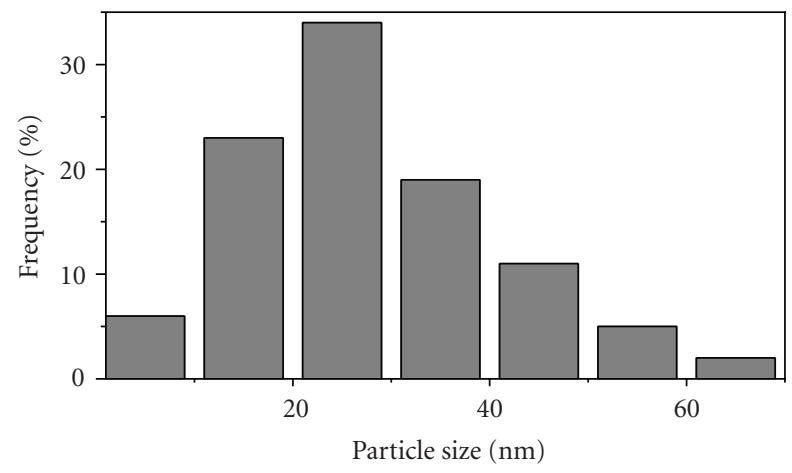

FIgURE 2: Particle size distribution of Ag nanoparticles.

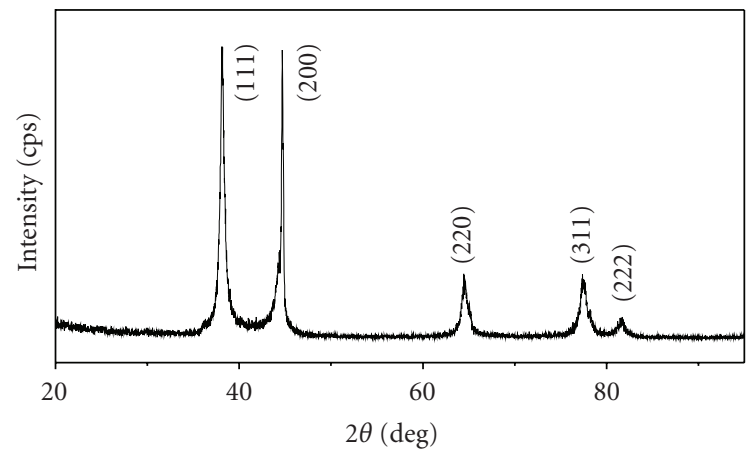

FIGURE 3: XRD patterns of Ag nanoparticles.

and small particles causes the widening of diffraction rings that made up of many diffraction spots, which indicate that the nanoparticles are polycrystalline structure. Electron diffraction reveals that each particle is composed of many small crystal nuclei, which is a convincing proof that the particles grow in an aggregation model.

From the data obtained by TEM micrographs, the particle size histograms can be drawn, and the mean size of the particles can be determined. Figure 2 shows the particle size distribution of $\mathrm{Ag}$ nanoparticles. It can be seen that the particle sizes range is from $5 \mathrm{~nm}$ to $65 \mathrm{~nm}$, and the median diameter (taken as average particle diameter) is about $26 \mathrm{~nm}$, being deduced from the images, which shows a relatively broad size distribution.

Figure 3 shows the typical X-ray diffraction pattern for the specimen. The diffraction peaks are broad, suggesting that the sample consists of very small particles. The major peaks of the pure Ag powders are observed. Five broad peaks with $2 \theta$ values of $38.14^{\circ}, 44.70^{\circ}, 64.57^{\circ}, 77.37^{\circ}$, and $81.69^{\circ}$ corresponding to the (111), (200), (220), (311), and (222) planes of the bulk Ag, respectively, which can be assigned to Ag FCC structure. The XRD pattern shows that the samples

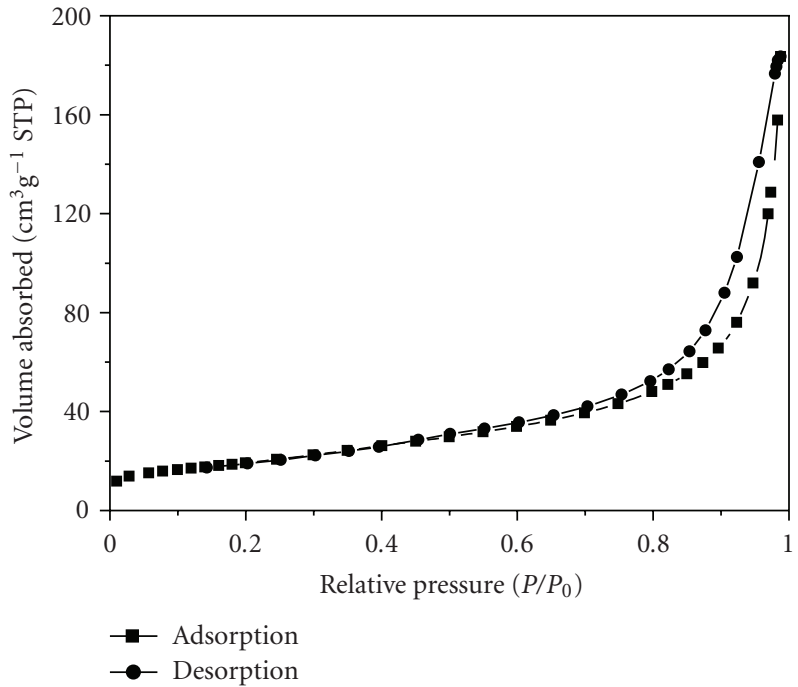

FIGURE 4: $\mathrm{N}_{2}$ adsorption-desorption isotherms of Ag nanoparticles.

are single phase, and no other distinct diffraction peak, except the characteristic peaks of FCC phase Ag, was found.

From the full width at half maximum, the grain size for the sample can be calculated from half widths of the major diffraction peak (111) according to Scherrer formula, $d=$ $K \lambda / B \cos \theta$, where $d$ is the grain size, $K=0.89$ is the Scherrer constant related to the shape and index (hkl) of the crystals, $\lambda$ is the wavelength of the $\mathrm{X}$-ray $(\mathrm{Cu} \mathrm{Ka}, 1.54056 \AA), \theta$ is the diffraction angle, and $B$ is the corrected full width at half maximum (in radian). The average crystallite size was found to be about $24 \mathrm{~nm}$, which is well consistent with the average particle diameter obtained from TEM images of Figure 2(a).

According to the electron diffraction formula $R d_{\mathrm{hkl}}=$ $\lambda L$ and the X-ray diffraction $\lambda=2 d_{\mathrm{hkl}} \cos \theta$, the values of interplaner spacings $d_{\mathrm{hkl}}$ were calculated from the diameters of the diffraction rings as well as from the results of the XRD analysis. For FCC structure, $d_{\mathrm{hkl}}=a / \sqrt{h^{2}+k^{2}+l^{2}}$, the lattice parameter $(a)$ can be calculated from measured values for the spacing of the (111) plane, respectively. Table 2 presents the results of the lattice parameter and the interplaner spacings measured in the TEM-SAED and XRD analyses, and compares them to standard ASTM data $(a=4.088 \AA)$, the lattice constriction was found.

The $\mathrm{N}_{2}$ absorption-desorption isotherms of the samples were measured by using the static volumetric absorption analyzer. Figure 4 shows the typical nitrogen sorption isotherms of Ag nanoparticles. It shows the sample presents typical IV adsorption, in the low-pressure region $\left(P / P_{0}<\right.$ $0.7)$. It can be seen from the graph that the isotherms relative flat, namely, the adsorption and desorption isotherms completely superposition, owing to the adsorption of the samples mostly occurs in the micropores. At the relative high pressure 
TABLE 2: Comparison of interplaner spacings $\left(d_{\mathrm{hkl}}\right)$ and the lattice parameter $(a)$ with standard ASTM data.

\begin{tabular}{lccc}
\hline Method & TEM $(\AA)$ & XRD $(\AA)$ & $\begin{array}{c}\text { ASTM standard } \\
\text { value }(\AA)\end{array}$ \\
\hline $\begin{array}{l}\text { Interplaner spacings } \\
\left(d_{\mathrm{hkl}}\right)\end{array}$ & 2.978 & 2.977 & 2.980 \\
Lattice parameter $(a)$ & 4.086 & 4.084 & 4.088 \\
\hline
\end{tabular}

TABLE 3: BET experimental results of Ag nanoparticles.

\begin{tabular}{lccc}
\hline Constant $C$ & $\begin{array}{c}\text { Monolayer } \\
\text { adsorption } \\
\text { volume } V_{m}\end{array}$ & $\begin{array}{c}\text { BET surface area } \\
S_{\mathrm{BET}}\end{array}$ & $\begin{array}{c}\text { Average particle } \\
\text { size } D_{\mathrm{BET}}\end{array}$ \\
\hline 32.7754 & $2.4258 \mathrm{~cm}^{3} / \mathrm{g}$ & $23.81 \mathrm{~m}^{2} / \mathrm{g}$ & $28 \mathrm{~nm}$ \\
\hline
\end{tabular}

TABLE 4: Pore structure parameters of Ag nanoparticles.

\begin{tabular}{lccc}
\hline $\begin{array}{l}\text { Cumulative } \\
\text { surface area of } \\
\text { pores } S_{\mathrm{BJH}}\end{array}$ & $\begin{array}{c}\text { Cumulative } \\
\text { pore volume of } \\
\text { pores } V_{\mathrm{BJH}}\end{array}$ & $\begin{array}{c}\text { Average pore } \\
\text { diameter } d_{\mathrm{BJH}}\end{array}$ & $\begin{array}{c}\text { Probability } \\
\text { pore size } D\end{array}$ \\
\hline $18.91 \mathrm{~m}^{2} / \mathrm{g}$ & $0.0882 \mathrm{~cm}^{3} \mathrm{~g}^{-1}$ & $18.7 \mathrm{~nm}$ & $23 \mathrm{~nm}$ \\
\hline
\end{tabular}

region $\left(P / P_{0}>0.7\right)$, due to the capillary agglomeration phenomenon, the isotherms increase rapidly and form a lag loop.

Figure 5 shows BET plots of Ag nanoparticles. The specific surface area of $\mathrm{Ag}$ nanopowder calculated using the multipoint BET-equation is $23.81 \mathrm{~m}^{2} / \mathrm{g}$. Assuming that the particles have solid, spherical shape with smooth surface, and same size, the surface area can be related to the average equivalent particle size by the equation $D_{\mathrm{BET}}=$ $6000 /\left(\rho \cdot S_{w}\right)$ (in $\mathrm{nm}$ ), where $D_{\mathrm{BET}}$ is the average diameter of a spherical particle, $S_{w}$ represents the measured surface area of the powder in $\mathrm{m}^{2} / \mathrm{g}$, and $\rho$ is the theoretical density in $\mathrm{g} / \mathrm{cm}^{3}$. Table 3 presents the BET experimental results of Ag nanoparticles. We noticed that the particle size obtained from the BET and the TEM methods agrees very well with the result given by $\mathrm{X}$-ray line broadening. The results of TEM observations and BET methods further confirmed and verified the relevant results obtained by XRD as mentioned above.

Figure 6 shows the typical BJH desorption pore size distribution curves of Ag nanopowder. From the curves, we can see that most of the micropores with a size smaller than $40 \mathrm{~nm}$, the probability pore size of which estimated from the peak position is about $23 \mathrm{~nm}$, and possesses a relatively narrow pore size distribution. Moreover, such micropores have not been observed within particles by TEM (see Figure 2). Therefore, these particles are actually grain clusters, that is, small polycrystals. Based on the $\mathrm{BJH}$ academic model, the property of the cumulative pore specific surface area, cumulative pore volume, average pore diameter, and the probability pore size of pores were calculated by $\mathrm{BJH}$ analysis method and summarized in Table 4.

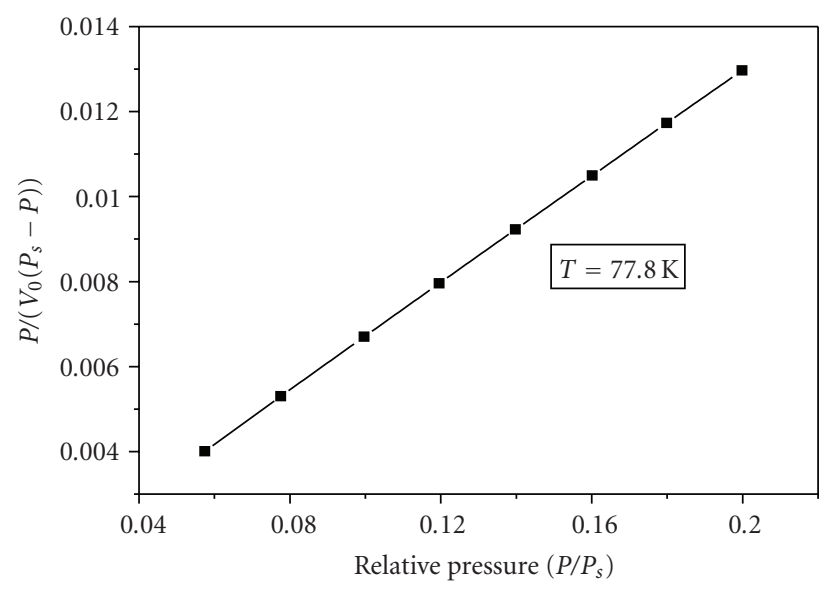

FIgURE 5: BET plots of Ag nanoparticles.

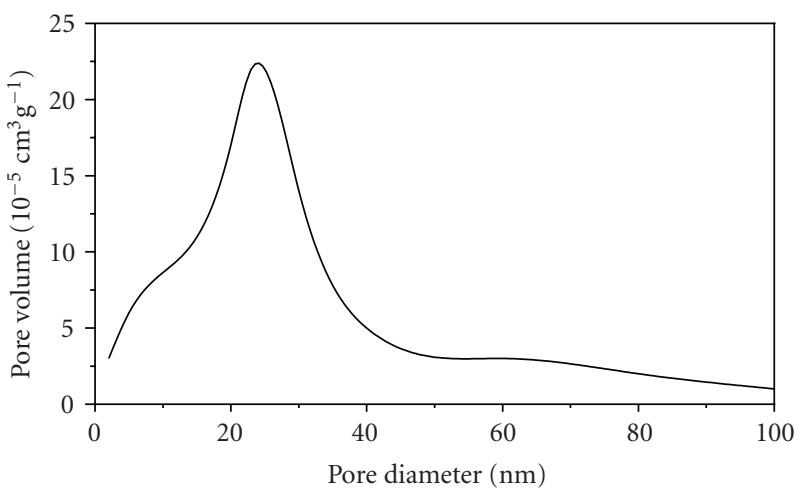

Figure 6: BJH pore size distribution curves of Ag nanoparticles.

\section{Conclusions}

(1) Silver nanoparticles were successfully prepared by confined arc plasma method in the protecting inert atmosphere. The nanoparticles prepared by this method achieved uniform particle size, higher purity, well-dispersed and quasispherical shape.

(2) The crystalline structure of the particles is FCC structure the same as that of the bulk materials, the particle size distribution ranges from 5 to $65 \mathrm{~nm}$ with average particle size about $26 \mathrm{~nm}$, the average equivalent particle size obtained from the TEM and confirmed by XRD and BET results.

(3) The specific surface area of the sample is $23.81 \mathrm{~m}^{2} / \mathrm{g}$ calculated from the BET adsorption equation. Based on the $\mathrm{BJH}$ academic model, the cumulative pore specific surface area, the cumulative pore volume, the average pore diameter, and the probability pore size of the samples are $18.91 \mathrm{~m}^{2} / \mathrm{g}$, $0.0882 \mathrm{~cm}^{3} / \mathrm{g}, 18.7 \mathrm{~nm}$, and $23 \mathrm{~nm}$, respectively.

\section{Acknowledgments}

This work was supported by the Key Project of Chinese Ministry of Education (no. 208151), Natural Science Foundation of Gansu Province, China (no. 2007GS04821), and Scientific 
Research Developmental Foundation of Lanzhou University of Technology (no. SB10200805).

\section{References}

[1] H. Gleiter, "Nanocrystalline materials," Progress in Materials Science, vol. 33, no. 4, pp. 223-315, 1990.

[2] Y. J. Chen, M. S. Cao, Q. Tian, T. H. Wang, and J. Zhu, "A novel preparation and surface decorated approach for $\alpha$ Fe nanoparticles by chemical vapor-liquid reaction at low temperature," Materials Letters, vol. 58, no. 9, pp. 1481-1484, 2004.

[3] W.-W. Zhang, Q.-Q. Cao, J.-L. Xie, et al., "Structural, morphological, and magnetic study of nanocrystalline cobalt-nickelcopper particles," Journal of Colloid and Interface Science, vol. 257, no. 2, pp. 237-243, 2003.

[4] Z. L. Cui, L. F. Dong, and C. C. Hao, "Microstructure and magnetic property of nano-Fe particles prepared by hydrogen arc plasma," Materials Science and Engineering A, vol. 286, no. 1, pp. 205-207, 2000.

[5] H. Gleiter, "Materials with ultrafine microstructures: retrospectives and perspectives," Nanostructured Materials, vol. 1, no. 1, pp. 1-19, 1992.

[6] B. J. Chen, X. W. Sun, C. X. Xu, and B. K. Tay, "Growth and characterization of zinc oxide nano/micro-fibers by thermal chemical reactions and vapor transport deposition in air," Physica E, vol. 21, no. 1, pp. 103-107, 2004.

[7] D. Chen, D. Chen, X. Jiao, Y. Zhao, and M. He, "Hydrothermal synthesis and characterization of octahedral nickel ferrite particles," Powder Technology, vol. 133, no. 1-3, pp. 247-250, 2003.

[8] M. S. Cao and Q. G. Deng, "Synthesis of nitride-iron nano meter powder by thermal chemical vapor-phase reaction method," Journal of Inorganic Chemistry, vol. 12, no. 1, pp. 8891, 1996.

[9] J. Karthikeyan, C. C. Berndt, J. Tikkanen, S. Reddy, and H. Herman, "Plasma spray synthesis of nanomaterial powders and deposits," Materials Science and Engineering A, vol. 238, no. 2, pp. 275-286, 1997.

[10] H. Zheng, J. Lang, J. Zeng, and Y. Qian, "Preparation of nickel nanopowders in ethanol-water system (EWS)," Materials Research Bulletin, vol. 36, no. 5-6, pp. 947-952, 2001.

[11] G. F. Gaertner and H. Lydtin, "Review of ultrafine particle generation by laser ablation from solid targets in gas flows," Nanostructured Materials, vol. 4, no. 5, pp. 559-568, 1994.

[12] J. L. Katz and P. F. Miquel, "Syntheses and applications of oxides and mixed oxides produced by a flame process," Nanostructured Materials, vol. 4, no. 5, pp. 551-557, 1994.

[13] B. Günther and A. Kumpmann, "Ultrafine oxide powders prepared by inert gas evaporation," Nanostructured Materials, vol. 1, no. 1, pp. 27-30, 1992.

[14] D. Vollath and K. E. Sickafus, "Synthesis of nanosized ceramic oxide powders by microwave plasma reactions," Nanostructured Materials, vol. 1, no. 5, pp. 427-437, 1992.

[15] D.-H. Chen and X.-R. He, "Synthesis of nickel ferrite nanoparticles by sol-gel method," Materials Research Bulletin, vol. 36, no. 7-8, pp. 1369-1377, 2001.

[16] I. Bica, "Nanoparticle production by plasma," Materials Science and Engineering B, vol. 68, no. 1, pp. 5-9, 1999.

[17] X. Li and S. Takahashi, "Synthesis and magnetic properties of Fe-Co-Ni nanoparticles by hydrogen plasma-metal reaction," Journal of Magnetism and Magnetic Materials, vol. 214, no. 3, pp. 195-203, 2000.
[18] Z. Q. Wei, H. X. Qiao, and P. X. Yan, "Particle size and microstructure of Ni nanoparticles by anodic arc plasma," Acta Metallurgica Sinica, vol. 18, no. 3, p. 209, 2005.

[19] Z. Wei, T. Xia, L. Bai, J. Wang, Z. Wu, and P. Yan, "Efficient preparation for Ni nanopowders by anodic arc plasma," Materials Letters, vol. 60, no. 6, pp. 766-770, 2006.

[20] A. Anders and J. W. Kwan, "Arc-discharge ion sources for heavy ion fusion," Nuclear Instruments and Methods in Physics Research Section A, vol. 464, no. 1-3, pp. 569-575, 2001.

[21] C. Kaito, "Coalescence growth mechanism of smoke particles," Japanese Journal of Applied Physics, vol. 24, no. 3, pp. 261-264, 1985.

[22] J. H. J. Scott and S. A. Majetich, "Morphology, structure, and growth of nanoparticles produced in a carbon arc," Physical Review B, vol. 52, no. 17, pp. 12564-12571, 1995. 

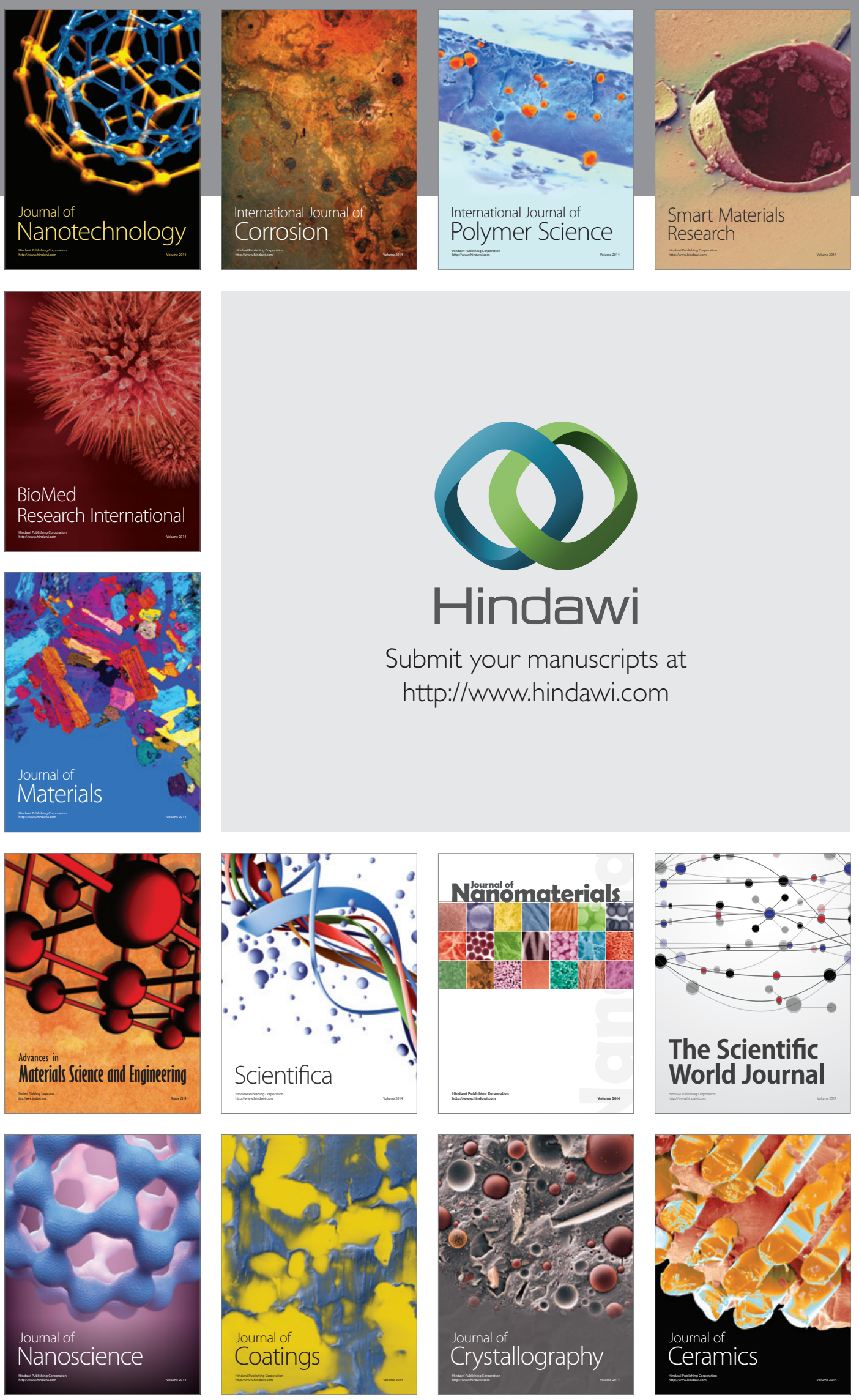

The Scientific World Journal

Submit your manuscripts at

http://www.hindawi.com

\section{World Journal}

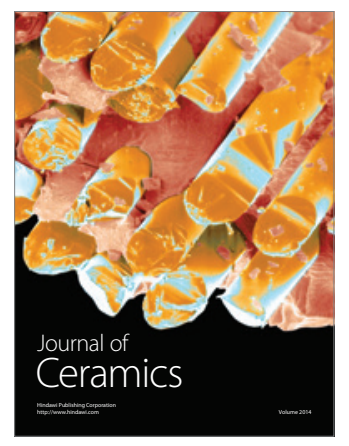

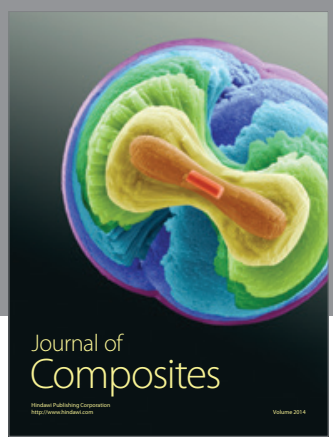
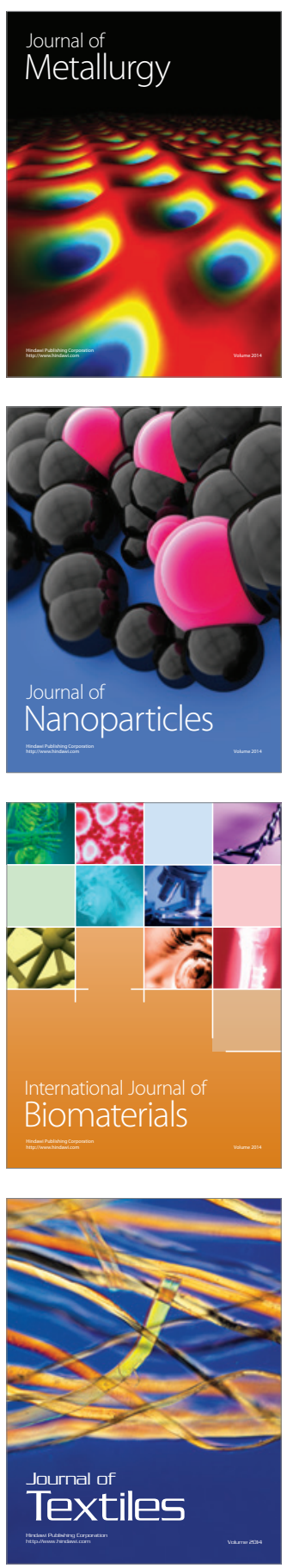